Abstract P105 Table 1 Outcomes for direct access pulmonary function testing

\begin{tabular}{|c|c|c|c|c|c|}
\hline Diagnosis & Referring GP & Laboratory & $\begin{array}{l}\text { Agreement pre- and } \\
\text { post-test diagnosis? }\end{array}$ & & $\begin{array}{l}100 \% \text { of patients would have been referred to chest clinic without this service. } \\
\text { Was this referral pathway changed? }\end{array}$ \\
\hline COPD & 11 & 8 & $\begin{array}{l}\text { Abnormal: abnormal } \\
\text { (same) } 11(61 \%)\end{array}$ & & $13(72 \%)$ \\
\hline Asthma & 5 & 3 & $\begin{array}{l}\text { Abnormal: abnormal } \\
\text { (different) } 3(17 \%)\end{array}$ & & $5(28 \%)$ \\
\hline $\begin{array}{l}\text { Fibrotic lung } \\
\text { disease }\end{array}$ & 0 & 0 & Abnormal; normal $2(11 \%)$ & & $\begin{array}{l}\text { This means that } 72 \% \text { of referrals have not required a chest } \\
\text { clinic referral because of this new service. }\end{array}$ \\
\hline Normal & 0 & 4 & & & \\
\hline Other & 2 & 3 & & & \\
\hline \multicolumn{6}{|c|}{$\begin{array}{l}\text { All GPs who have completed questionnaires were either satisfied (15\%) or very satisfied }(85 \%) \text { with regard to referral process, waiting time, management plan given and outcome of plan. No } \\
\text { negative responses were given. }\end{array}$} \\
\hline Patient comments: & $\begin{array}{l}\text { "Quick } \\
\text { appointment } \\
\text { given" }\end{array}$ & $\begin{array}{l}\text { "Very efficient } \\
\text { service" }\end{array}$ & $\begin{array}{l}\text { "Very good } \\
\text { approach" }\end{array}$ & $\begin{array}{l}\text { "Staff very } \\
\text { helpful" }\end{array}$ & $\begin{array}{l}\text { "Pleased with knowledge } \\
\text { and manner of physiologist" }\end{array}$ \\
\hline GP comments: & $\begin{array}{l}\text { "Excellent } \\
\text { service, } \\
\text { Thank you" }\end{array}$ & $\begin{array}{l}\text { "Very useful } \\
\text { service" }\end{array}$ & $\begin{array}{l}\text { "You are all } \\
\text { wonderful" }\end{array}$ & $\begin{array}{l}\text { "Very good } \\
\text { service" }\end{array}$ & \\
\hline
\end{tabular}

Practices to Respiratory Physiology. Hitherto, patients have been referred to Respiratory Clinic; most have Pulmonary Function Testing in a linked appointment on the same day. An audit of these patients showed $30 \%$ of referrals were immediately discharged back to the GP and could have been diagnosed and managed in primary care (estimated total saving of $£ 10000$ a year).

Aims for the LIP service More accurate diagnosis of respiratory disease in primary care. More appropriate management pathways for respiratory patients, with enhanced access to smoking cessation services, COPD respiratory nurse specialists and pulmonary rehabilitation services. Ultimately, this will result in a reduction in hospital admissions due to better diagnosis and management in primary care. The aim was to reduce referrals to the Chest Clinic by $25 \%$. To provide a quality service to the GPs and patients.

Methods Referrals for pulmonary function testing were received directly from Primary Care. Quality assured tests were performed: spirometry, gas diffusion and static lung volumes. At the point of testing, patients received detailed information regarding their results and diagnosis from a trained respiratory physiologist, giving an opportunity to have one to one conversations regarding fears or concerns about their diagnosis. Tests were reviewed by a respiratory consultant and a fully interpreted report Faxed to referring team. If Chest Clinic referral was advised, the cost of the services was deducted from the Chest Consultation tariff. Therefore the service is at least cost neutral.

Results (See Abstract P105 table 1).

Conclusions This service has been successfully set up, with a steady referral stream of patients from primary care. The main difficulty encountered has been awareness levels in primary care, despite promotion through standard channels. Outcomes show a high level of satisfaction with the service from both patients and GPs. $75 \%$ of patients who used this service have subsequently been managed within primary care, with an estimated cost saving of $£ 1800$ to the health economy.

\section{P106 REDUCTION OF INAPPROPRIATE OXYGEN PRESCRIPTIONS BY A HOME OXYGEN SERVICE}

doi:10.1136/thoraxjn-2011-201054c.106

A Y Yates, C C Chamberlain, H G B Bakere. RD\&E Foundation Trust, Exeter, UK

Introduction and Objectives Home Oxygen in England costs around $£ 110$ million yet it is estimated that $30 \%$ of patients derive no clinical benefit $(\mathrm{DH}, 2010) .{ }^{1}$ In addition oxygen can be harmful if used inappropriately. The RD\&E Home Oxygen Service was set up in 2008 to provide a comprehensive oxygen assessment service for all adult patients requiring Long Term Oxygen Therapy (LTOT) including the provision of follow-up in the patient's home. 1044 patients have been seen by this service so far, and 63 concentrators removed following assessment by the home oxygen team.

Methods We evaluated retrospectively the patients who had oxygen removed. The characteristics of this population were investigated including reason for removal, whether an oxygen assessment had been undertaken and the appropriateness of oxygen prescription.

Results On assessment 85\% (54/63) had saturations $>92 \%$ and $49 \%$ $(31 / 63)$ were not using their oxygen. Of the 63 patients who had their oxygen removed more patients (53\%) had their LTOT initiated in Primary Care. These patients therefore received no formal assessment prior to initiation. When assessed $67 \%$ did not meet the criteria for LTOT. Of the 63 those established on LTOT by the Home Oxygen Service, it was primarily in the context of an inpatient stay. In these cases adequate follow-up and review allowed oxygen to be removed once stable. The economic saving from the removal of inappropriate oxygen is considerable. $60 \%(38 / 60)$ no longer required oxygen therapy amounting to a cost saving of $£ 20330$. 39\% were re-categorised to a lower tariff but 17\% proved difficult to wean and continued on Short Burst Oxygen (SBOT) despite inadequate evidence for this therapy.

Conclusion Our experience suggests as integrated oxygen service allows a more robust approach to oxygen prescription and monitoring. It reduces the risk of harm from oxygen prescription, and unnecessary prescriptions. This has both financial and medical

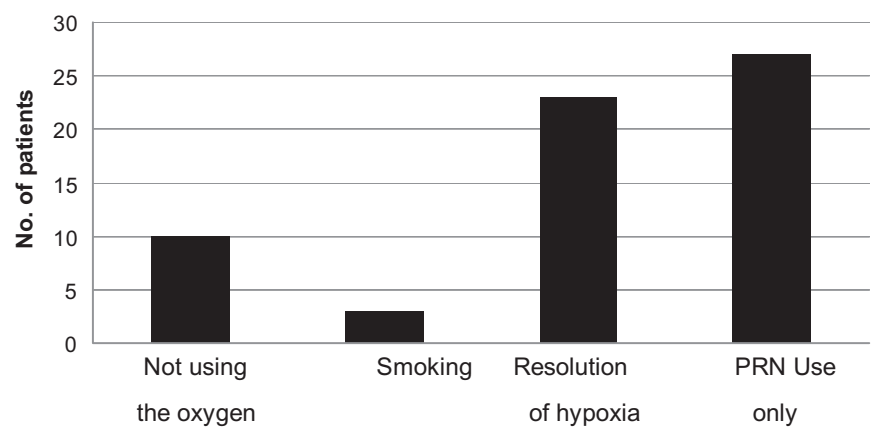

Abstract P106 Figure 1 Reason for removal of oxygen concentrator. 
benefits. Direct prescription of LTOT from primary care by comparison carries a risk of inadequate initial assessment and follow-up.

\section{REFERENCE}

1. Department of Health. 'Consultation on a strategy for Services for chronic Obstructive pulmonary disease (COPD) in England'. 2010. http://www.dh.gov.uk/ prod consum dh/groups/dh digitalassets/@dh/@en/documents/digitalasset/ dh__113279.pdf (accessed $1 \overline{4}$ Jul 2011) very good therapeutic response, we have observed significant improvement in lung functions.

\section{P108 OMALIZUMAB FOR SEVERE ALLERGIC ASTHMA: COST-EFFECTIVE OR PRICELESS?}

doi:10.1136/thoraxjnl-2011-201054c.108

J Miles, D Green. North Manchester General Hospital, Manchester, UK

\section{Managing asthma: inhaled therapy and beyond P107 EFFECTIVENESS OF OMALIZUMAB ON ASTHMA CONTROL AND LUNG FUNCTION IN SEVERE ALLERGIC ASTHMA PATIENTS IN THE CZECH REPUBLIC}

doi:10.1136/thoraxjnl-2011-201054c.107

${ }^{1}$ V Sedlák, ${ }^{2}$ NCTA. ${ }^{1}$ Department of Respiratory Medicine, University Hospital, Hradec Králové, Czech Republic, ${ }^{2}$ Czech Severe Asthma Collaborating Group, Prague, Czech Republic

Introduction Anti-IgE therapy (omalizumab) is indicated for severe persistent allergic asthma, which is uncontrolled despite appropriate therapy according to current GINA guidelines.

Aim of this study Aim of this study was to describe changes of selected parameters $\left(\mathrm{FEV}_{1}\right.$, life quality and $\left.\mathrm{FeNO}_{50}\right)$ in all patients treated with omalizumab in the Czech Republic for more than 12 months in a real life clinical setting.

Methods Data of 127 patients treated 12 months by omalizumab in eight Czech centres were prospectively observed in Czech Anti-IgE Registry and analysed. Respiratory specialist and allergist together decided indication of anti- $\operatorname{IgE}$ therapy after extensive evaluation process in each patient.

Results Median IgE level was $223 \mathrm{IU} / \mathrm{ml}$, all patients experienced during previous year at least two exacerbation treated by oral steroid burst. 69 patients were dependent on oral steroids, mean dose $5 \mathrm{mg}$ prednisolone/day. After 12 months of omalizumab therapy $\mathrm{FEV}_{1}$ improved from $65 \%$ to $72 \%(p<0.001)$, asthma control test changed from 13 to 18 points score $(\mathrm{p}<0.001)$ and $\mathrm{FeNO}_{50}$ decreased from 48 to $32 \mathrm{ppb}(\mathrm{p}=0.001)$. Emergency visits, steroid bursts for asthma exacerbation and mean oral steroid dose were lower after the 12 months of therapy as well (all $\mathrm{p}<0.001$ ). Observed side effects were mild (headache, weight gain) in $21.3 \%$ patients. Overall response to anti-IgE therapy measured by clinical evaluation of treatment benefit was $80.8 \%$.

Conclusion Rigorous selection of candidates for anti-IgE therapy based on consensus of allergology and respiratory specialists leads to
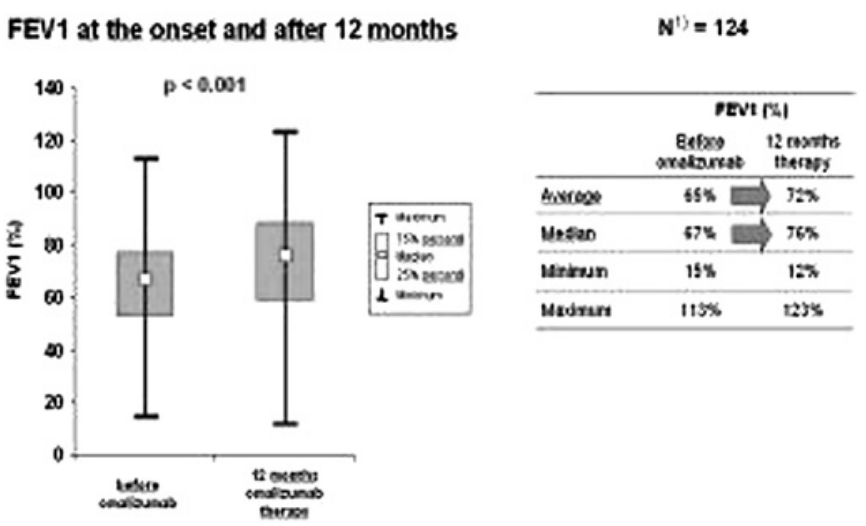

Abstract P107 Figure 1 Spirometry after12 months of omalizumab therapy.
Background Omalizumab is licensed for the treatment of severe allergic asthma to help reduce severe exacerbations. However the decision as to whether to consider Omalizumab therapy is based on a 16 week assessment period with no reference to the licensed indication at all! We were therefore keen to examine omalizumab efficacy in terms of exacerbation reduction in our severe asthma clinic.

Methods 40 patients had received omalizumab treatment for at least 12 months, on the basis of a successful 16 week assessment period. Hospital and GP records were scrutinised to assess exacerbation frequency and unscheduled hospital attendance before and after treatment. Costs for asthma admissions, attendance for clinic and price per omalizumab vial were analysed. In addition a repeat patient survey was undertaken to assess satisfaction with therapy and our service using a previously validated tool. ${ }^{1}$

Results Complete data was available for 20 patients. A sequential eduction in unscheduled hospital; contacts was seen throughout the first year following commencement of omalizumab. Average cost savings on unscheduled hospital attendances were $£ 2500$ per annum. Average costs of attendance for injections were $£ 2080$ per annum. Treatment costs varied between $£ 3250$ and $£ 26000$ per patient per annum. We did not have data on the absenteeism rates from those patients currently in full or part time employment. Patient satisfaction with both Omalizumab and the clinic set up remained high as in keeping with our previous assessment.

Conclusions

1. Omalizumab does reduce exacerbation frequency in patients with severe allergic asthma.

2. Patients are extremely satisfied with the efficacy of therapy.

3 . The costs of reduced unscheduled care offset the costs of extra planned attendances for injections.

4. Although an expensive treatment, there may be many potentially hidden physical, social and economic benefits of omalizumab therapy.

5. Sophisticated health economic analysis is required to pursue this hypothesis.

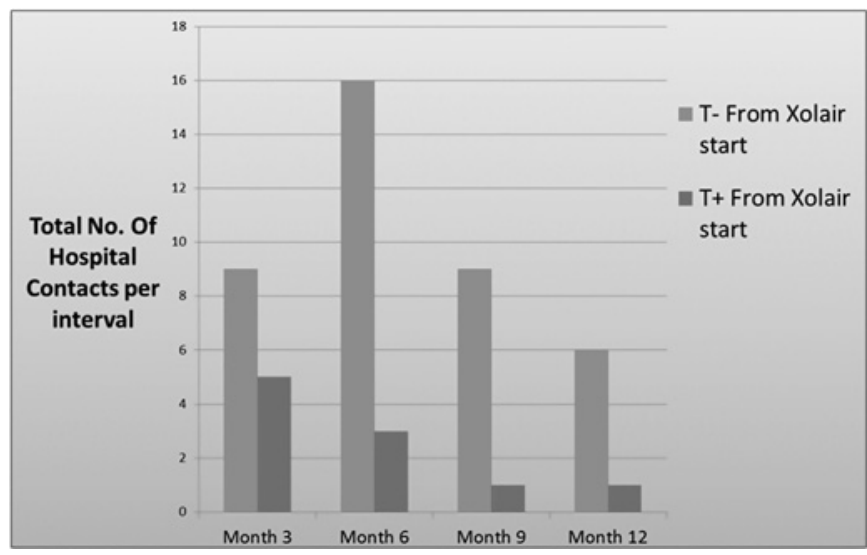

Abstract P108 Figure 1 Total hospital contacts by intervals: first year before and first year after the start of treatment. 